\title{
Saúde Pública na Fronteira: as epidemias de Corumbá nos documentos históricos $(1856-1922)$
}

Lúcia Salsa Corrêa*

O propósito deste artigo é enfatizar a importância dos documentos históricos sobre saúde pública na fronteira e, em especial, sobre as epidemias que foram recorrentes no porto de Corumbá no período de 1856 a 1922. Além disso, é interessante observar a clara e estreita relação entre os assentamentos pioneiros na fronteira oeste do Brasil e as ocorrências de surtos epidêmicos de doenças procedentes dos portos fluviais da Bacia do Prata, como também a vulnerabilidade do porto de Corumbá frente às distintas formas de interferência externa.

Palavras-chave: Fronteira; saúde pública; documentos históricos.

The purpose of this article is to emphasize the importance of the public health frontier documents, especially about the Corumbá's harbour recurrent epidemics within 1856 and 1922. Moreover, it is interesting to observe the trans- rises na saúde pública em região de fronteira, como o sul de Mato Grosso e de sua porta de comunicação com o resto do mundo - o porto de Corumbá, foram relativamente documentadas no período de 1856 a 1922, possibilitando aos historiadores um rico material de pesquisa. Por isso o propósito deste artigo, após revisão e atualização documental ${ }^{1}$, destina-se a enfatizar e estimular uma releitura destas fontes ou, no dizer de Maria Yedda Linhares, rejuvenescê-las ${ }^{2}$.

Os acervos mais interessantes que dispõem desse material são: o Arquivo Público do Estado de Mato

\footnotetext{
* Professora Titular de História aposentada da UFMS, endereço eletrônico valmir.correa@uol.com.br

${ }^{1}$ Originalmente publicado na Revista do Instituto Histórico e Geográfico de Mato Grosso do Sul, n. 1, dezembro 1998, p. 165-177.

${ }^{2}$ LINHARES, Maria Yedda. A pecuária e a produção de alimentos na Colônia. Resumos do I Congresso Brasileiro de Historia Econômica e de II Conferenciam Internacional de Historia de Empresas. São Paulo, 7-10 set. 1993, USP-UNICAMP, p. 26.
} 
parent and narrow relationship between the pioneer's settlements at the Brazilian west frontier and the occurrence epidemic diseases coming from the Bacia do Prata's harbour, as also the vulnerability of the Corumbá's harbour regarding a variety of international interferences.

Key words: Frontier; public health; historical documents.

Grosso (APMT) em Cuiabá e que hoje dispõe de excelente local e organização; o outro, o arquivo da Câmara Municipal de Corumbá-MS (ACMC) ainda aguarda um local adequado para seu deposito, não possui organização, mas se apresenta acessível. Além disso, nos arquivos públicos de São Paulo e do Rio de Janeiro (Arquivo Nacional-AN, e Biblioteca Nacional-BN) podem ser encontrados livros de viajantes, jornais, correspondências e relatórios avulsos que ilustram o período e os problemas de saúde pública em foco.

Entretanto, a pesquisa com registros dos séculos XIX ao XX sobre Mato Grosso e Mato Grosso do Sul, especialmente sobre sociedade e economia, enfrenta outras importantes dificuldades, tais como a ausência de documentação seriada. Uma soma de fatores diversos explica o problema, dentre eles os episódios conturbados da guerra, as disputas por terras e as rebeliões políticas, as crises econômico-financeiras e de saúde pública. A vida das pessoas que se estabeleceram nos portos dos grandes rios da Bacia do Prata, ou nos imensos sertões de Mato Grosso, pantanais ou cerrados, foi periodicamente perturbada e uma das suas consequências foi a destruição deliberada ou casual de arquivos de juizados, de cartórios, de escolas, de igrejas e de outras agencias do estado e instituições regionais. O contexto histórico e político do sul de Mato Grosso ilustrado nesses registros, a partir de meados do século XIX até os anos de 1920, demonstrou a existência de uma clara e estreita relação entre a formação de assentamentos pioneiros na fronteira oeste e os problemas com a saúde pública decorrentes dos contatos através da via fluvial. Essa relação foi apontada com frequência em áreas de fronteira pioneira, mas também em portos marítimos e fluviais.

A região fronteiriça mato-grossense durante muito tempo dependeu da navegação para a sobrevivência dos seus núcleos de povoamento, tanto dos pequenos como dos grandes rios tributários da Bacia do Prata, com o aproveitamento de sua extensa malha fluvial. Contudo, a despeito do favorecimento destes abundantes recursos naturais, a sua imensa zona fronteiriça sofreu as consequências da irregularidade de comunicação, do seu isolamento e da falta de segurança. 
Pelo Tratado de Comércio e Navegação Brasil-Paraguai, firmado em 6 de abril de 1856, tais problemas foram enfrentados, porém criando novas preocupações em função da comunicação direta com portos marítimos nacionais e estrangeiros. Nesse sentido, as autoridades paraguaias procuraram garantir medidas diversas, incluindo providências sanitárias preventivas para impedir a entrada de doenças em caráter epidêmico pelo curso marítimo/ fluvial Rio de JaneiroAssunção-Corumbá. $\mathrm{O}$ anexo $\mathrm{n}^{\circ} 3$ dos originais deste tratado especificava as medidas sanitárias adotadas pelo governo da república paraguaia para os navios que procediam dos portos brasileiros, nos seguintes termos:

\section{Instrucções para ocommandante da policiafluvial das Tres-Bocas}

Assumpção, 10 de Agosto de 1856

Ficando aberta e franca para o Brasil, pelo seu tratado de 6 de Abril ultimo com o Paraguay, a navegação pelo rio deste nome ás suas possessões no Alto Paraguay, as disposições policiaes existentes na commandancia da policia fluvial das Tres-bocas para as outras nacionalidades serão tambem guardadas para com a bandeira brasileira.

As epidemias de febre amarella e cholera morbus, que desde alguns annos devastão o Imperio do Brasil, e principalmente o Rio de Janeiro, exigem medidas convenientes para evitar que se introduzão na Republica [do Paraguai], como poderia acontecer chegando os vapores daquelle porto em 15 dias á embocadura do rio Paraguay; e a este respeito o commandante da polícia fluvial das Tres-Bocas observará as disposições seguintes:

$1^{\circ}$ Todas as embarcações de commercio brasileiro procedentes do Imperio do de saude do lugar de sua procedencia.

$2^{\circ}$ Os capitães ou patrões, tanto das embarcações de commercio como de guerra, que tenhão certificado de saude, o mandarão com os outros documentos do navio ao commandante da policia fluvial, que precederá neste caso como até aqui para deixa-los seguir viagem.

$3^{\circ}$ Como é notorio que todas as costas do Brasil estão infectadas pela febre amarella e cholera-morbus, e sendo duvidoso que haja cessado em um ou outro lugar, se os capitães ou patrões dos navios não apresentarem certificados de 
saude ao commandante da policia fluvial, este os intimará para fundearem na altura e no sul da pequena ilha que fórma o Paranami, onde se conservarão pelo tempo de 20 dias, incluidos os que gastarem para chegar até a confluencia do Paraguay no Paraná; de sorte que se empregarem 20 dias na viagem, e não se houver declarado um caso de epidemia, poderão seguir.

$4^{\circ}$ No caso de que se haja declarado á chegada, ou durante a quarentena, algum caso de febre amarella, ou de chorela-morbus, o commandante ou patrão do navio avisará immediatamente içando uma bandeira negra, ao commandante da policia fluvial, e este ao chefe do estado-maior do exercito nacional acampado em Humaitá.

$5^{\circ}$ Não são exceptuados destas disposições os navios de guerra brasileiros e os de outras nacionalidades, procedentes do Brasil,que possão chegar até Assumpção, segundo a lei da República.

$6^{\circ} \mathrm{A}$ intimação de fundear ao sul da peque ilha que forma o Paranami realisar-se-há do escaler em que há de ir o encarregado de fazê-la por uma simples remessa destas instrucções que serão impressas.

$7^{\circ} \mathrm{A}$ correspondencia e os documentos do navio posto em quarentena receber-se-hao com as precauções de costume em taes casos, e se remetterão ao chefe do estado-maior do exercito nacional para que as faça seguir a seu destino.

$8^{\circ}$ Se o commandante ou patrão da embarcação que estiver em quarentena occultar os casos de epidemia que se declarem, ficará sujeito ás penas com que se castiga este crime em todas as nções civilisadas.

$9^{\circ}$ Concluido o despacho da embarcação para seguir sua viagem, far-se-há constar a entrega destas instrucções no rol da equipagem.

Carlos Antonio Lopez ${ }^{1}$

No âmbito da navegação fluvial platina, na metade de século XIX, destacou-se o porto de Corumbá como ponto estratégico e entreposto comercial de maior expressão em todo o sul da província de Mato Grosso, desfrutando não apenas das vantagens dessa situação, mas também sofrendo as suas consequências negativas. Os riscos de epidemias eram, portanto, iminentes e Corumbá tornou-se bastante vulnerável a estes episódios.

\footnotetext{
${ }^{1}$ Medidas sanitarias adoptadas pelo governo da Republica para os navios que procedem dos portos do Brasil. Tratado de Amizade, Comercio e Navegação Brasil-Paraguai. ANEXO nº 3 Regulamentos da Republica do Paraguai sobre o transito de navios brasileiros e paraguayos que se dirigem as possessões brasileiras, p. 5, Lata 1870, APMT.
} 
Um dos casos mais notórios ocorreu durante a invasão paraguaia em solo mato-grossense, iniciada em 1864-1865, quando civis e soldados de ambos os lados foram castigados pelas epidemias, uma delas a da varíola, a partir do núcleo portuário de Corumbá. Durante a retomada da vila pelas forças brasileiras em 1867, a varíola contaminou a diminuta população, militares e civis, espalhando-se depois por toda a província e atingindo Cuiabá com um incalculável número de vítimas ${ }^{2}$.

Um relatório de 1872 de vereadores de Corumbá, com o balanço das consequências da guerra na fronteira, afirmou que a varíola teria causado enormes danos a alguns grupos indígenas com pesadas perdas humanas, haja vista as aldeias Guaikurú, Xamacoco, Guaná e Guató quase dizimadas nessa época.

As antigas aldeias de indios existentes em Albuquerque [Corumbá], com a invasão paraguaya desapparecerão, e seos restos existem hoje espalhados pelo Municipio, confundidos coma demais população, empregando-se os indivuduos adultos do sexo masculino principalmente como tripulantes das canôas e nos trabalhos de lavouras: sobre esses a catechese nada mais tem de fazer. Existem porem ainda, em estado nomade os restos da grande nação guaycurú, habitante da margem esquerda do rio Paraguay, do Fórte de Coimbra para baixo, e em estado errante os restos da nação Chamocôcos habitante da margem direita do mesmo rio. Dizemos restos porque ambas estas naçãoes foram cruelmente dizimadas pela epidemia de bexigas, alem de que os Guaycurús pela circubstancia que lhes é particular, de que as mulheres só depois de uma avançada idade deixão que vinguem os frustos da propria concepção, tendem a desapparecer....

Existem mais nas margens da lagoa Gahyba e Mandioré... no rio S. Lourenço os diminutos restos da nação Guató, que a epidemia de bexigas fez quasi completamente desapparecer... ${ }^{3}$

\footnotetext{
2 "Luctamos aqui com uma medonha epidemia de bexigas, a qual do dia 14 de agosto a 17 do corrente nos arrebatou numero de victimas superior a 1.500, só nesta capital." In Officio do Dr. J.V. Couto de Magalhães dirigido ao Presidente da Provincia de Matto Grosso em Cuiabá, 20 de setembro de 1867. Officios da Provincia de Mato Grosso. APESP. No ano de 1881 ainda surgiam casos de variolosos em Corumbá, para os quais chegou a ser instalado um lazareto fora do perímetro urbano. Ver Officio da Intendencia Municipal de Corumbá em 14 de Desembro de 1881. Livro de Registro de Officios da Camara Municipal, 1880-1894, Fls. 80. ACMC.

${ }^{3}$ Relatorio dos vereadores João José Lopez Carneiro da Fontoura e Jacinto Pompeo de Camargo sobre o estado da lavoura do Municipio de Corumbá encaminhado ao Presidente da Provincia em $1^{\circ}$ de Novembro de 1872. APMT.
} 
E, ainda nesse mesmo ano de 1872, o inspetor da Alfândega de Corumbá comunicava que uma epidemia de febre amarela desenvolvia-se em Montevidéu e indicava medidas preventivas para resguardar o porto local ${ }^{4}$.

O desenvolvimento comercial do núcleo urbano de Corumbá configurou um dos traços marcantes da formação da sociedade da fronteira e da ocupação estratégica da extrema faixa sul de Mato Grosso. Este núcleo apresentou características únicas em toda a região e, mesmo sendo o principal entreposto mercantil de Mato Grosso desse final de século, viveu às voltas com problemas permanentes em decorrência de sua condição periférica no contexto do mercado platino ${ }^{5}$ e da ausência de uma infra-estrutura urbana e sanitária adequada às características de seu crescimento. A grande afluência de estrangeiros para o seu porto fluvial influenciou o modus vivendi local, expressando-se na paisagem urbana e no cosmopolitismo. As diferentes origens desses elementos imigrantes (paraguaios, bolivianos, argentinos, uruguaios e europeus de modo geral) e os contatos da região com as cidades portuárias do Prata possibilitaram o florescimento de Corumbá mas, por outro lado, tornaram-na vulnerável e afetaram de forma direta toda a população da fronteira mato-grossense. Assim, o porto de Corumbá foi ao mesmo tempo porta da prosperidade comercial e acesso de gravíssimas crises de saúde pública, conturbando a vida e o desenvolvimento econômico da localidade. A cada surto de moléstias que acometia da cidade, por exemplo, ocorria uma reação em cadeia provocando distúrbios na vida econômica com aumento abusivo dos gêneros de primeira necessidade, crises de abastecimento, aumento de alugueis e fretes, imposição de preços por comerciantes monopolistas, incluindo remédios e medidas destinadas a combater os gargalos da higiene pública, sobretudo nos portos e passagens da fronteira seca.

Uma expressiva maioria do contingente populacional de Corumbá, nos anos de 1860 a 1920, permaneceu longe das condições satisfatórias de sobrevivência, vivendo nos limites da miséria. Os relatórios da administração mu-

${ }^{4}$ Officio do Inspector d'Alfandega d'Albuquerque ao Presidente da Provincia, em 20 de Maio de 1872. APMT.

${ }^{5}$ A propósito do contexto da Bacia do Prata e das articulações econômicas que viabilizaram o movimento mercantil do porto de Corumbá, determinando sua posição singular no mercado mundial em fins do século XIX, ver CORRÊA, Lúcia Salsa. História e Fronteira: o sul de Mato Grosso. 1870-1920. Campo Grande: Editora da UCDB, 1999. 
nicipal não poupavam palavras para descrever e denunciar graves problemas sociais provocados pelo o fluxo sem controle de imigrantes, com a precariedade do abastecimento de água, com a ausência de saneamento básico da cidade e com a saúde pública e, além de tudo, a concentração da riqueza por um grupo reduzido de comerciantes resultante do comércio de importação e exportação de mercadorias. Contudo, as crises na saúde pública atingiram indistintamente ricos e pobres.

Um ofício do presidente da província de Mato Grosso, Hermes Ernesto da Fonseca, em 1877, afirmava haver em Corumbá sérios problemas com a população mais pobre e desamparada, mais suscetível às crises e epidemias.

A grande miseria que reina na ultima classe de moradores da Villa de Santa Cruz de Corumbá, quasi todos estrangeiros, e o facto asseverado por medicos de terem visto individuos succumbirem á fome e á molestia, completamente abandonados, sem remedios, trouxe a alguns distinctos e benemeritos cidadãos a ideia de fundar ali um estabelecimento de caridade para receber e soccorrer aquelles infelizes.... ${ }^{6}$

O sistema de abastecimento de água na localidade manteve-se por muito tempo deficiente e insalubre, explorado pela iniciativa particular e com a água retirada diretamente do rio, nem sempre em locais mais adequados. Para ser vendida à população e por preços altos, era

... recolhida em carretas ... com prejuizo da salubridade pública; em certas epocas do anno ella faz desenvolver inflamações intestinas e molestias peculiares a esta grave enfermidade ${ }^{7}$.

De todos os problemas apontados pelas autoridades locais, o mais grave residia na falta de manutenção e de controle das condições sanitárias do porto, onde atracavam embarcações de diversas origens e procedências. Em decorrência disso Corumbá foi assolada durante varias décadas por epidemias que provocaram profundas crises em sua organização social e econômica penalizando arduamente toda a comunidade local.

${ }^{6}$ Officio do Presidente da Provincia de Matto Grosso, Hermes Ernesto da Fonseca, em 18 de Setembro de 1877, AN

${ }^{7}$ Relatorio do Presidente da Camara Municipal de Corumbá. Em 24 de Setembro de 1884. Manuscrito. In: Livro $n^{\circ} 205$ Copias de Relatorios da Camara, projectos de leis e outros, 1875-1888. ACMC. 
Em geral, os relatórios das doenças que grassaram em caráter epidêmico na cidade citavam sempre números altos de vítimas e muitos óbitos e, ainda, denunciavam o agravamento dos problemas sociais da cidade. Além disso, a câmara municipal enfrentava de forma costumeira a falta de recursos financeiros nas épocas adversas das epidemias, necessitando recorrer aos empréstimos sacados nas grandes casas comerciais locais que funcionavam como agencias bancarias para atender às demandas excepcionais com socorros públicos ${ }^{8}$.

Um dos aspectos mais dramáticos das epidemias parece ter sido o abandono de doentes pobres pelas ruas e até de cadáveres insepultos. Havia, ainda, falta crônica de medicamentos e de hospitais mesmo provisórios. Além disso, as fugas em massa da população urbana para os campos e pantanais foram muito comuns nessas ocorrências, o que causou maior descontrole sobre a disseminação da doença e dos óbitos.

... os mortos e os doentes ... são em grande escala abandonados da maneira a mais iniqua; ... diversos doentes ... são abandonados no solo, a titulo de não serem parentes dos que os cercavão, ou são abandonados igualmente, por não serem patricios d'aquelles a quem servirão. ${ }^{9}$

As repercussões desses procedimentos levavam as autoridades de Corumbá a temer consequências mais drásticas, como a completa evacuação da cidade $^{10}$.

Do período de 1867, ocasião da retomada de Corumbá, até a década de 1920, a cidade padeceu com o surgimento de mais de trinta surtos epidêmicos, dos quais a varíola foi recorrente, malgrado as campanhas de vacinação e os esforços infrutíferos das autoridades municipais. O cólera também castigou

\footnotetext{
${ }^{8}$ Copia do Officio do Presidente da Camara Municipal de Corumbá, José Joaquim Rabelo ao Presidente da Provincia de Matto Grosso, em 25 de Fevereiro de 1887, Correspondencia da Camara com a Presidencia da Provincia. In Livro $n^{\circ} 169$, 1886-1890, fl. 23. ACMC.

${ }^{9}$ Officio do Dr. Manoel Joaquim dos Santos dirigido ao Vice-Presidente em exercicio Luiz Augusto Esteves da Camara Municipal de Corumbá, em 8 de Dezembro de 1886. Requerimentos e concessão de terreno, 1886-1906. ArCba.

10 "Esta cidade em breve ficará abandonada, servindo os factos que se tem dado de tristes commentarios pelos Estrangeiros aqui residentes." Relatorio... 1884 citado In Livro $n^{\circ} 205$ Copias de Relatorios da Camara, projectos de leis e outros, 1875-1888. ACMC.
} 
numerosas vezes a comunidade corumbaense, embora os documentos que registraram essas ocorrências apenas mencionassem o desenvolvimento de febres intestinas.

\section{Quadro das Epidemias em Corumbá \\ (1867 - 1920)}

\begin{tabular}{|l|l|}
\hline \multicolumn{1}{|c|}{ EPIDEMIAS } & \multicolumn{1}{c|}{ ANOS } \\
\hline Cólera & 1886,1887 \\
\hline Coqueluche & 1901 \\
\hline Febre Amarela & $1872,1890,1912$ \\
\hline Febres em geral & $1882,1889,1912$ \\
\hline Gripe Influenza & $1890,1897,1915,1919,1920$ \\
\hline Peste Bubônica & 1902 \\
\hline Sarampo & $1879,1901,1913$ \\
\hline Tifo & $1907,1912,1913,1915$ \\
\hline Varíola & $1867,1872,1881,1884,1890,1891,1892,1897,1899,1900,1901,1903.1906,1907,1908$ \\
\hline
\end{tabular}

Fonte: CORREA, Lucia Salsa. Corumbá: um núcleo comercial na fronteira de Mato Grosso (1870-1920). Dissertação de Mestrado,FFLCH- USP, S. Paulo, 1980, 154p.

Como visto, a devastadora epidemia do cólera em Corumbá dos anos de 1886-1887, relatada em diversos registros detalhados, provocou a mais profunda crise local desde a invasão e ocupação paraguaia, desenvolvendo-se de forma avassaladora.

Tendo apparecido aqui a 5 do corrente [de dezembro de 1886] alguns casos de -cholera morbus- e causando isso um grande panico a ponto de muitas familias correrem de suas casas abandonando a cidade em procura de abrigo a tão terrivel epedemia e prevendo nessas retiradas maiores calamidades procurei persuadir a muitas do quanto era funesta essa medida e fiz publicar mesmo a 7 do corrente um boletim ..., acomselhando limpeza e fumêgações como os melhores preservativos de tal enfermidade pois com tais providencias pouco ou nada se devia temer./ ... A mortalidade tem attengido a mais de cem até hoje, so dos que morrem dentro desta cidade, por que os do Ladario e fazendas não são enterrados aqui; proporcionalmente é menor o numero dos casos fatais, pois a principio contava-se por mortos os doentes, ao passo que hoje que o povo ou descura menos dos seus enfermos ou a molestia ataca com caracter mais benigno a proporção dos mortos vai demenuindo em relação ao numero 
de enfermos; achão-se todos mais animados apesar de existir doente grande numero de pessôas. ${ }^{11}$

Um cálculo aproximado estimou mais de mil pessoas atingidas pelo cólera nessa ocasião, embora as autoridades não tivessem meios confiáveis e eficientes para avaliar as perda reais e os danos causados nessas circunstâncias.

Há muito a nossa cidade precisa de saneamento que não se tem podido realisar. Pelo obituário comparado ao Rio de Janeiro, cidade taxada de pestilenta, vê-se que aqui morre sempre 8 a 10 vezes mais que naquella cidade. ${ }^{12}$

Somados aos problemas de saúde pública decorrentes da epidemia do cólera, apareciam igualmente outros fatores complicadores da situação aflitiva de Corumbá. A doença se fazia acompanhar pela carestia de alimentos e de mercadorias essenciais, pelo abastecimento irregular e alta generalizada de preços no mercado local.

... depois de haver grassado com grande intensidade a epedemia do cholera morbus desde o dia 7 de Desembro ultimo, parece extincto o mál, visto não ter havido caso algum desde o dia 2 do corrente, mas não pensam assim os facultativos que ainda julgão em incubação, entretanto faz-se sentir a carestia e a falta completa dos generos alimenticios, os quais tem subido a preços fabulosos com exceção da carne... ${ }^{13}$

Nos anos de 1889-1890 a febre amarela fez grande número de vítimas, desencadeando mais uma crise em Corumbá e, na prática, repetiram-se os episódios dramáticos com a ocorrência do cólera de 1886-1887. Neste contexto de crise aguda a cidade chegou a receber auxílio diretamente do Rio de Janeiro, através do paquete Ladario que atracou no porto corumbaense em 2 de dezembro de 1889 , trazendo medicamentos, médicos, farmacêuticos e gêneros alimentícios ${ }^{14}$.

${ }^{11}$ Cópia do Relatorio do Presidente da Camara Municipal de Corumbá, Antonio Antunes Galvão, em 14 de desembro de 1886. Livro de Registro de documentos da Camara Municipal de Corumbá com a Presidencia da Provincia de Matto Grosso, 1886-1890. Fls. 8-13. ACMC.

${ }^{12}$ Relatorio do Presidente da Camara Municipal de Corumbá, Antonio Antunes Galvão aos demais Vereadores, em 7 de Janeiro de 1887. ACMC.

${ }^{13}$ Copia do Officio do Presidente da Camara Municipal de Corumbá, em 19 de Janeiro de 1887 ao Presidente da Provincia de Matto Grosso. Livro $n^{\circ} 168$, citado. ACMC.

${ }^{14}$ Officio do Presidente da Camara Municipal, José Joaquim Rabello, ao Presidente da Provincia de Matto Grosso. Livro $n^{\circ} 169$, citado. ACMC. 
Ainda assim, conforme os relatórios sobre a febre amarela, permanecia na cidade a mesma precariedade de saneamento básico e do abastecimento de água, possibilitando a proliferação de diversas outras doenças em caráter epidêmico, que provocavam verdadeiras calamidades na região fronteiriça.

...as [más] condições prendiam ás habitações em Corumbá e ao habito de pouco asseio da mór parte de sua população, bem como a falta d'agua, sua má qualidade, a imundicie da cidade e o nenhum cuidado da limpesa publica e domestica, constituirão focos permanentes de infecções ... ${ }^{15}$

Em 1890, a Delegacia de Higiene de Corumbá acusava a existência de pessoas vitimadas pela influenza (gripe) procedentes de Assunção, no Paraguai, onde esta moléstia se propagava ${ }^{16}$. No ano de 1891 reapareceu a varíola em Corumbá acompanhada das sequelas idênticas às crises anteriores. Repetiram-se, assim, as desolações sofridas pela camada mais pobre de sua comunidade, afetando igualmente todos os setores da sociedade local.

O traço recorrente das crises na saúde pública em Corumbá, sem dúvida, foi a carestia de alimentos e demais gêneros de primeira necessidade que flagelava a população, ocasiões nas quais os comerciantes locais promoviam altas desenfreadas nos preços das mercadorias disponíveis ${ }^{17}$. Dessa forma, os altos riscos das epidemias, o fechamento de grande parte das casas comerciais, o decréscimo e mesmo a paralisação dos transportes e do movimento portuário (e, como consequência imediata, o rompimento dos contatos com outras localidades e com o exterior), eram compensados no comércio pela grande especulação de preços, sobretudo, dos medicamentos. Os grandes comerciantes, capazes de realizar estoques e controlar o fluxo de importações do porto exercendo o monopólio do comércio regional, desencadeavam uma ação exploradora do mercado local, prática essa denunciada pelas próprias autoridades municipais quando ocorriam abusos ilimitados.

${ }^{15}$ Officio do Dr. Alberto Saboia Viriato de Medeiros, Delegado de Higiene de Corumbá dirigido á Camara Municipal, em 15 de Janeiro de 1890. Portarias e Documentos avulsos, 1890. Idem.

${ }^{16}$ Officio do Delegado de Hygiene Dr. Alfredo Ferreira do Valle ao Intendente Municipal de Corumbá, em 4 de Março de 1890. Caixa 1890, citada. Idem.

${ }^{17}$ Officio do Presidente da Camara Municipal de Corumbá ao Presidente do Estado, em 14 de Fevereiro de 1893. Livro de Registro de Officios da Camara Municipal de Corumbá, 1890-1894. Idem. 
As denúncias apareceram com maior intensidade nos documentos relatados às autoridades da província de Mato Grosso, nos períodos críticos, e nessas ocasiões surgiram até mesmo denúncias de manipulação de informações que beneficiavam comerciantes especuladores ${ }^{18}$. No geral, entretanto, a estreita relação entre os grandes comerciantes atravessadores do mercado regional e o poder constituído na municipalidade gerava a conivência com as práticas monopolistas e exploradoras. Essa cumplicidade ficava explicitada em denúncias ocasionais da imprensa local:

... as condescendencias descommunais, as tolerancias desordenadas, contra lei postas em estylo, unicamente para não desgostar pessoas altamente collocadas, são o maior mal de nossa terra; mal cujos máos resultados não repercutem tão somente nos filhos desta provincia; tambem férem directamente a outros, que na mesma provincia habitão. ${ }^{19}$

Uma das formas encontradas para superar a carestia de gêneros alimentícios e remédios em Corumbá, decorrente destes episódios e da paralisação do fluxo fluvial, era o recurso aos socorros públicos solicitados aos governos provincial e central. Na ocasião do cólera de 1886, por exemplo, foi realizada a distribuição de grande quantidade de víveres aos pobres e indigentes em Corumbá, e parte desses gêneros foi vendida a preços normais à pequena parcela da comunidade que tinha algum recurso para adquiri-los, medida que pretendia colocar um freio na onda de especulação e na alta generalizada de preços na praça local ${ }^{20}$.

$\mathrm{Na}$ fase republicana, de forma regular, a câmara municipal e a intendência de Corumbá solicitavam o apoio do governo estadual para executar medidas preventivas, tais como obras de saneamento básico e abastecimento de água, a fim

18 " ....alguns medicos e particulares para algum fim inconfessavel tem feito echo de que a epidemia ainda reina nesta cidade..." Copia do Off. do Presidente da Camara Municipal de Corumbá, Generoso Nunes Nogueira, dirigido ao Presidente e Vereadores da Camara Municipal de Miranda, em 24 de Janeiro de 1887. Livro de Registro, citado. Idem.

${ }^{19}$ Editorial do Corumbaense, Anno VII, n 48, Corumbá, 23 de Dezembro de 1886, p. 1. Idem.

${ }^{20}$ Tabela demonstrativa do modo que forão destrebuidos os generos remettidos Pela Prezidencia da Provincia a Camara Municipal de Corumbá pela Lancha Santa Cruz, em 22 de Janeiro de 1887. In Officio do Presidente da Camara Municipal de Corumbá ao Presidente da Provincia de Matto-Grosso, em 31 de Janeiro de 1887. Officios dirigidos á Camara,1874. Idem. 
de que não se repetissem os fatos das epidemias anteriores, alegando os graves prejuízos causados à cidade, ao comércio e os

.. damnos irreparaveis que afectam a economia vital do paiz, depauperando-lhe as forças e afugentando os estrangeiros, de cujo concurso muito necessitam os paizes americanos, que almejam progredir. ${ }^{21}$

No ano de 1897, a câmara municipal registrava a notícia de que a varíola havia novamente surgido em alguns pontos centrais do Paraguai e recomendava a vacinação preventiva da população corumbaense ${ }^{22}$. A varíola, de fato, reapareceu na cidade em dezembro de 1899 até setembro de 1900, mesmo com o recebimento de vacinas provenientes de Assunção e com a vacinação de 418 pessoas que voluntariamente se apresentaram na câmara municipal. Contudo, em relatório ao intendente municipal, o Dr. Santos Malhado, presidindo uma comissão de socorros públicos, queixava-se do aumento de casos de enfermos e da relutância da maioria da população em receber a vacina, necessitando inclusive de aparato policial para executar seu trabalho de convencimento da população para a prevenção da varíola ${ }^{23}$.

No ano seguinte, 1901, a intendência acusava em seu relatório anual à câmara municipal, a ocorrência de um surto de sarampo e coqueluche entre crianças da comunidade, registrando muitos óbitos ${ }^{24}$.

Já o ano de 1902 ficou marcado pela passagem da peste bubônica por Corumbá, afetando a população e desorganizando as atividades locais à semelhança das situações críticas anteriores.

Não obstante as bôas condições do nosso clima e a excellente situação topographica da nossa cidade, o estado sanitario, assim como nos dous annos anteriores este terceiro, prestes a findar, infelizmente deixa também registrado

\footnotetext{
${ }^{21}$ Copia do Officio dos Vereadores João Pedro Cavassa, Miguel Henriques de Carvalho e Salvador Paes de Campos, dirigido ao General Antonio Maria Coelho, em 29 de Julho de 1890. Livro Registros de officios de diversas autoridades, 1890-1894. Idem.

${ }^{22}$ Acta da sessão ordinaria da Camara Municipal de Corumbá, em 17 de novembro de 1897. Livro de Actas $n^{\circ} 183$ de Actas das Secções da Camara, 1895-1898. Fls. 88-89. Idem.

${ }^{23}$ Relatorio do Dr. Domevil José dos Santos Malhado ao Intendente Municipal de Corumbá, João Pedro Cavassa, em $1^{\circ}$ de Outubro de 1900. Requerimentos e officios dirigidos á Camara. Idem.

${ }^{24}$ Relatorio do anno de 1901 da Intendência Municipal de Corumbá ao Presidente e demais Vereadores da Camara Municipal, em 31 de Outubro de 1901. Officios Dirigidos á Camara Municipal de Corumbá. Idem.
} 
um período calamitoso na memoria da população, em consequencia do apparecimento do peor dos flagellos da humanidade - a peste bubonica - que vem produzindo regular numero de victimas ${ }^{25}$.

O comandante do $7^{\circ}$ Distrito Militar de Corumbá, no ano de 1903, em seu relatório ao chefe do Estado Maior do Exército, descrevia as condições apresentadas pela região, do ponto de vista estratégico-militar, como ideais para sediar o Distrito Militar da Fronteira. Todavia, do ponto de vista da saúde pública, apontava a insalubridade da região e a vulnerabilidade de seu porto como desestímulo ao serviço de soldados e oficiais que temiam a sua fama de cidade pestilenta.

...o facto de ser o porto de entrada do Estado e o mais importante, pelo que se está desenvolvendo extraordinariamente a mesma cidade, tanto em commercio como em população, convencem de que aqui deve ser mantida, ao menos por muitos annos, a séde do Districto militar... [Corumbá] ... não se pode chamar uma cidade salubre, principalmente para o soldado, cuja vida é mais ou menos sedentaria no quartel ou acampamento. D'ahi resulta que as praças de pret são facilmente affectadas de beri-beri, febres intermittentes, palustres, etc... Isto justifica em parte o terror de que se possuem os officiaes e as praças que têm de vir para este Estado e até os d'elle naturaes, que vêm de outras guarnições...No ano de 1906, comerciantes comprometidos com o abastecimento de água da cidade assinaram um relatório encaminhado à câmara municipal, para justificar o atraso das obras a que estavam obrigados e arrolavam diversos fatores como a crise financeira do país, a alta de preços de mercadorias importadas e dos fretes, as questões políticas geradoras de grande instabilidade no estado mato-grossense e na fronteira e as epidemias

...que, infelizmente têm assolado esta cidade durante o período dupra referido, entre os quaes destaca-se a terrivel peste levantina, outros [causas], finalmente ligadas as inundações periodicas do rio Paraguay, sobresahindo a do anno passado [1905], que produzio a completa desorganização dos serviços, prejudicando lavradores, creadores, negociantes, industriaes, operarios, em summa, toda a população do Municipio, não sendo pequeno o número dos habitantes que ficarão reduzidos á extrema pobreza, lamentando-se que, em face d'uma

${ }^{25}$ Relatorio do Intendente Geral do Municipio apresentado a Camara Municipal em sua legislatura ordinaria do corrente anno, em 31 de Outubro de 1902. Caixa 1876-1886. Idem. 
calamidade pública, não viesse o Governo Federal em soccorro da população flagellada. ${ }^{26}$

A intendência de Corumbá, no ano de 1907, admitia estar ainda lutando para debelar a varíola na cidade com casos recorrentes desde 1903, sempre acometendo a população mais pobre e sem recursos. O mesmo ocorria com a febre tifóide, presente anualmente na cidade. Tal situação perdurou até por volta de 1920, quando se repetiram numerosos casos de tifo e outras febres gastrointestinais, como eram registradas as doenças de caráter epidêmico surgidas nessa época em Corumbá.

As autoridades locais, embasadas em relatórios de saúde pública, responsabilizavam a comunidade por não acatar as imposições legais que determinavam a vacinação obrigatória e normas básicas de higiene pública, tanto nos logradouros públicos como nos estabelecimentos e residências particulares. Estas normas referiam-se ao fornecimento/abastecimento de água potável, ao lixo despejado nas ruas e praças públicas, ao hábito de muitos cidadãos criarem porcos e outros animais em suas casas sem o menor cuidado e sem confinamento, e mais outros hábitos pouco recomendáveis.

Além do mais, dentre todos esses graves problemas, havia a existência de diversas pessoas acometidas da hanseníase convivendo no seio da comunidade local sem o tratamento adequado, que na época determinava o isolamento dos doentes. O relatório do intendente de Corumbá, no ano de 1922, manifestava sua preocupação com o desenvolvimento da hanseniase em Corumbá e em Ladário, acusando a comunidade de conviver de forma promíscua e descuidada com portadores do mal de Hansen ${ }^{27}$.

Estas constantes crises de epidemias e de carestia em Corumbá criaram, por sua vez, um clima propício à violência, com a frequente ocorrência de tumultos, tanto pelo terror da contaminação e desconhecimento da eficácia de medidas preventivas, como pela desigual distribuição e venda de gêneros de socorros públicos.

\footnotetext{
${ }^{26}$ Requerimento enviado ao Presidente e de mais Membros da Camara Municipal de Corumbá, em 27 de Setembro de 1906. Caixa 1895-1908. ACMC.

${ }^{27}$ Relatorio anual da Intendência de Corumbá a Câmara Municipal, em 6 de Novembro de 1922, pelo Intendente João Christiao Carstens. ACMC.
} 
Nesse sentido, no âmbito da saúde pública, expressou-se de forma bem clara a condição de fronteira aberta do porto e, consequentemente, da cidade de Corumbá vulnerável a distintas formas de interferência externa. Além disso, houve as limitações da medicina e das providências necessárias tomadas na época, muitas vezes sem o devido conhecimento das causas e das sequelas das doenças, ou mesmo da origem da contaminação.

É importante lembrar que as mesmas doenças que castigaram Corumbá ocorreram sob a forma de epidemias também em outras regiões da Europa e dos Estados Unidos da América, como o cólera, a febre tifóide, gripe, varíola durante diversos períodos ao longo do século XIX. No Rio de Janeiro, o cólera atingiu grande parte da população em 1855, e na cidade de Santos, no estado de São Paulo, a febre amarela e a peste bubônica flagelaram sua população em 1889. O movimento dos portos e do comércio em escala mundial foi um fio condutor que irradiou as epidemias por todos os cantos do planeta, sobretudo para as Américas. A internacionalização das águas do rio Paraguai foi, portanto, uma forma de Corumbá inserir-se no circuito dos portos nacionais e internacionais, participando do movimento mundial das comunicações modernas, dos intercâmbios comerciais e do processo de imigração.

Os registros que testemunharam as ocorrências de surtos epidêmicos em Corumbá são, de fato, esclarecedores quanto à natureza e ao caráter da sociedade que ali se formou desde as suas origens, quando se constituiu num assentamento fronteiriço singular, projetando-se como ponta de lança dos domínios lusitanos no período colonial. Em fase posterior, na segunda metade do século XIX, Corumbá assumiu um papel mais relevante nos sertões mato-grossenses em face de sua situação de entreposto comercial de abastecimento regional e corredor de exportação de matérias-primas, crescimento que não foi acompanhado de melhoria na qualidade de vida de seus habitantes. Esses registros são, portanto, muito eloquentes e desvendam a natureza dos núcleos populacionais da fronteira mato-grossense, lugares onde viver nos fins do século XIX e nos primórdios do $\mathrm{XX}$ foi um desafio permanente e uma aventura real. 